\title{
Peptides ${ }^{14}$ VIDLL ${ }^{18}$ and 96 FEAAAL 101 defined as epitopes of antibodies raised against amino acid sequences of enterotoxigenic Escherichia coli colonization factor antigen I fused to Salmonella flagellin
}

\author{
Maria G. Luna, ${ }^{1}+$ Luis C. S. Ferreira, ${ }^{1}$ Darcy F. Almeida' and Anna Rudin ${ }^{2}$
}

Author for correspondence: Maria G. Luna. Tel: +55 21 5876380. Fax: +55 215876476.

e-mail: luna@uerj.br

1 Instituto de Biofisica Carlos Chagas Filho, Universidade Federal do Rio de Janeiro, Cidade Universitária, Rio de Janeiro, 21949-900, RJ, Brazil

\section{Department of Medical} Microbiology and Immunology, Göteborg University, S-413 46 Goteborg, Sweden

\begin{abstract}
Antibodies raised against four hybrid Salmonella flagellins carrying amino acid sequences derived from the fimbrial subunit of the colonization factor I antigen (CFAI) of enterotoxigenic Escherichia coli (ETEC), i.e. hybrid flagellins Fla I (aa 1-15), Fla II (aa 11-25), Fla III (aa 32-45) and Fla IV (aa 88-102), were not able to inhibit the in vitro binding of CFA/l-expressing ETEC bacteria to enterocyte-like Caco-2 cells. However, one of the hybrid flagellins (Fla II) was recognized by a previously described anti-CFAl subunit mAb (S-CFAVI 17:8) which was able to block adhesion of CFAl-expressing bacteria to Caco-2 cells and to bind to the amino acid sequence ${ }^{15}$ IDLLQ ${ }^{19}$ of the CFA/I fimbrial subunit. Pepscan analysis of antibodies raised against the hybrid flagellins Fla II and Fla IV showed that they were specific for the sequences ${ }^{14}$ VIDLL ${ }^{18}$ and ${ }^{96}$ FEAAAL ${ }^{101}$, respectively, of the CFAI fimbrial subunit. Thus, the discrepancy in the abilities of the anti-Fla II serum and the mAb S-CFA/I 17:8 to block binding might be ascribed to their slightly different fine specificity for epitopes.
\end{abstract}

Keywords: enterotoxigenic Escherichia coli, CFA/I fimbriae, flagellin, Salmonella, monoclonal antibodies

\section{INTRODUCTION}

Enterotoxigenic Escherichia coli (ETEC) is one of the most common causes of acute diarrhoea in children in developing countries and in travellers who visit ETECendemic areas (Black, 1990, 1993). Adherence of bacteria to the epithelial surface of the small intestine and delivery of toxins are the two most important events in ETEC pathogenesis. Colonization of the human small intestine by ETEC involves several antigenically different fimbrial or non-fimbrial adhesins collectively termed colonization factors (CFs), but individually called either colonization factor antigens (CFAs), coli surface (CS) antigens or putative colonization factors (PCFs) (Gaastra \& Svennerholm, 1996). Since mucosal antibodies to CFs are protective against ETEC disease, these antigens have been included in vaccines (Holmgren \&

\footnotetext{
†Present address: Disciplina de Microbiologia e Imunologia, Faculdade de Ciências Médicas, Universidade do Estado do Rio de Janeiro, Av. 28 de Setembro 87 fundos $-3^{\circ}$ andar, 20551-030, Rio de Janeiro, RJ, Brazil.

Abbreviations: CFA, colonization factor antigen; ETEC, enterotoxigenic Escherichia coli.
}

Svennerholm, 1996). However, protection conferred by immunization with CFs is restricted to those strains expressing homologous adhesins (Svennerholm et al., 1989).

The CFA/I fimbria is one of the most frequently found CFs in epidemiological studies and also one of the best characterized at the molecular level. It has a rigid structure with a diameter of $7 \mathrm{~nm}$ and is composed of many copies of a single $15 \mathrm{kDa}$ subunit which shares extensive amino acid sequence similarity with the subunits of other CFs, for example CS1, CS2, CS4, CS17 and PCFO166 (McConnell et al., 1989; Gaastra \& Svennerholm, 1996). The CFA/I fimbria is polar with a single receptor-binding domain located at the tip of the fimbrial rod (Bühler et al., 1991; Marron \& Smyth, 1995).

In contrast to $\mathrm{mAbs}$ raised against intact fimbriae, $\mathrm{mAbs}$ against dissociated CFA/I subunits were shown to crossreact with several CFs and could inhibit the adhesion of ETEC expressing homologous and heterologous CFs to enterocyte-like Caco-2 cells and isolated human jejunal enterocytes (Rudin et al., 1994, 1996). One of these 
mAbs, S-CFA/I 17:8, bound to a continuous epitope of the CFA/I subunit composed of the amino acid sequence ${ }^{15}$ IDLLQ $^{19}$ (Rudin \& Svennerholm, 1996). However, immunization with a synthetic peptide corresponding to the first $25 \mathrm{~N}$-terminal amino acids of the CFA/I subunit did not generate antibodies with the required specificity to block the adhesion of CFA/I-expressing bacteria to Caco-2 cells (Rudin \& Svennerholm, 1996).

Attenuated Salmonella strains can induce a broad immune response after oral administration and represent a convenient and low-cost alternative means of presenting heterologous antigens (Hoiseth \& Stocker, 1981). Moreover, the insertion of heterologous linear epitopes in Salmonella flagellin has been shown to induce humoral immune responses against several antigens, such as cholera toxin (Newton et al., 1989), hepatitis B virus surface antigen (Wu et al., 1989), influenza virus haemagglutinin (McEwen et al., 1992) and streptococcal M protein (Newton et al., 1991). Purified hybrid Salmonella flagellins carrying linear epitopes of the CFA/I fimbria have also been shown to induce antibodies against the CFA/I fimbrial subunit after parenteral immunization of mice (Luna et al., 1997).

In this study we analysed mouse antisera against hybrid flagellins with CFA/I-derived amino acid inserts for inhibition of binding to Caco-2 cells. In addition, the epitope specificity of the CFA/I-specific antibodies raised against the hybrid flagellins was evaluated by the Pepscan technique.

\section{METHODS}

Bacterial strains and plasmid. The flagellin-negative strain Salmonella dublin aroA SL5928 was used as a carrier of plasmids encoding the hybrid flagellins (Newton et al., 1989). The plasmid pLS408 has a deletion of a 48 bp EcoRV fragment in the central hypervariable region of the $f l i C(\mathrm{H} 1-d)$ flagellinencoding gene. Therefore, this plasmid contains a unique EcoRV restriction site between two codons of the flagellin gene, into which in-frame insertions of oligonucleotides encoding CFA/I sequences could be introduced. Construction and characterization of the Salmonella strains harbouring the recombinant pLS408-derived plasmids were carried out as previously described (Luna et al., 1997). The flagellin encoded by plasmid pLS408 was referred to as Fla 30 . The flagellins containing CFA/I-derived sequences were named Fla I (aa 115), Fla II (aa 11-25), Fla III (aa 32-45) and Fla IV (aa 88-102). For flagellin purification, the Salmonella strains were grown at $37^{\circ} \mathrm{C}$ in Luria-Bertani broth (Difco) supplemented with $25 \mu \mathrm{g}$ ampicillin $\mathrm{ml}^{-1}$.

The ETEC strains 258909-3 (CFA/I, O128:H?, $\mathrm{ST}^{+} / \mathrm{LT}^{+}$) (Gothefors et al., 1985) and the corresponding CFA/I-negative mutant 258909-3M (Lopez-Vidal et al., 1988) were used in assays of inhibition of binding to Caco-2 cells and immunoelectron microscopy. The ETEC strains were grown on Casamino acids/yeast extract agar plates (CFA agar) at $37^{\circ} \mathrm{C}$ overnight (Evans et al., 1979).

Flagellin and CFA/I fimbriae preparations. The different flagellins were purified by acid cleavage, as described by Ibrahim et al. (1985). The hybrid flagellin preparations were analysed by SDS-PAGE before immunization to control for any possibility of degradation of the protein. Protein concentrations were determined by the Lowry method. The CFA/I fimbriae were purified essentially as described by Evans et al. (1979). Briefly, bacteria grown on CFA agar were homogenized with a blender and centrifuged at $12000 \mathrm{~g}$ for $20 \mathrm{~min}$. The cell-free supernatant fraction was ammonium-sulphate-precipitated (at 20 and $40 \%$ saturation), and after centrifugation at $12000 \mathrm{~g}$ and dialysis, the pellet was further purified by gel filtration in a DEAE-Sephadex column or by ultracentrifugation in a $\mathrm{CsCl}$ gradient (density $1.3 \mathrm{~g} \mathrm{~cm}^{-3}$ ). The concentration of the fimbriae was determined by an inhibition ELISA using a highly purified lyophilized fimbrial preparation as a reference (Lopez-Vidal et al., 1988).

Antibody preparations. mAbs against CFA/I subunits, i.e.

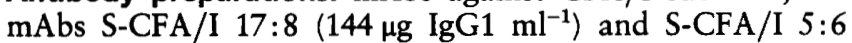

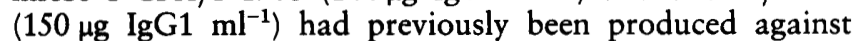
guanidine-hydrochloride-dissociated subunits of CFA/I fimbriae (Rudin et al., 1994). The anti-peptide antiserum was previously raised in rabbits against a synthetic CFA/I peptide consisting of the first $25 \mathrm{~N}$-terminal amino acids of the subunit (Rudin \& Svennerholm, 1996). Antisera against each of the modified flagellins were raised in female BALB/c mice after four intraperitoneal immunizations with $10 \mu \mathrm{g}$ purified flagellin (Luna et al., 1997). The first dose was given in complete Freund's adjuvant, and 3 weeks later a second dose was administered in incomplete Freund's adjuvant. Ten days later two additional doses without adjuvant were given with a $4 \mathrm{~d}$ interval. The animals were sacrified 1 week after the last immunization and blood was drawn by heart puncture. All sera were incubated with a CFA/I-negative strain (258909$3 \mathrm{M})$ and heat-inactivated before use, as previously described (Rudin \& Svennerholm, 1996). Immunization of BALB/c mice with isolated hybrid flagellins resulted in the production of specific IgG responses against CFA/I fimbrial subunits (Luna et al., 1997). The CFA/I-subunit-specific IgG titres generated with hybrid flagellins Fla II and Fla IV were higher than those generated with hybrid flagellins Fla I and Fla III (1/6400 and $1 / 1600$ versus $1 / 100$ and $1 / 800$, respectively). No CFA/Ispecific antibody titre was detected in antiserum raised against Salmonella flagellin without an insert (Fla 30) (Luna et al., 1997).

Agglutination tests. A $10 \mu$ sample of a bacterial suspension $\left(10^{10}\right.$ c.f.u. $\left.\mathrm{ml}^{-1}\right)$ of each recombinant $S$. dublin strain expressing flagellin with or without an insert and of the flagellinnegative strain was mixed with the same volume of undiluted mAbs or antiserum on a glass slide at room temperature. The reaction was considered positive when agglutination was macroscopically visible within $2 \mathrm{~min}$. The bacterial strains mixed with saline served as parallel negative controls.

Inhibition of adhesion to Caco-2 cells. Caco-2 cells were grown for 14-16 d in Dulbecco's modified Eagle's medium containing foetal calf serum $(10 \%, v / v)$ and glutamine $(1 \%$, $\mathrm{w} / \mathrm{v}$ ) in eight-well chamber slides (Nunc) in $7 \% \mathrm{CO}_{2}$ at $37^{\circ} \mathrm{C}$. A suspension of $10^{7}$ bacteria $\mathrm{ml}^{-1}$ in culture medium containing $0.5 \%$ D-mannose was mixed with an equal amount of diluted antiserum and incubated at room temperature for $20 \mathrm{~min}$. The mixture was then added to the Caco- 2 cells, washed with Eagle's medium and incubated at $37^{\circ} \mathrm{C}$ for $3 \mathrm{~h}$. After five washes, cells were fixed in methanol, stained with $10 \%(\mathrm{v} / \mathrm{v})$ Giemsa and examined by oil-immersion light microscopy to determine bacterial adherence. The percentage of epithelial cells with at least one adhering bacterium was determined by counting 10 randomly chosen microscopical fields with approximately 100 cells per field. Each antiserum was tested at least in duplicate and all assays were performed in a blind manner. 
Table 1. Reactivity in ELISA of mAbs and sera against CFAl fimbrial subunits and a synthetic $\mathrm{N}$-terminal CFAll peptide with hybrid flagella bearing CFAl amino acid sequences, and their capacity to agglutinate $S$. dublin strains expressing hybrid flagellins

Flagellins bearing CFA/I-derived sequences are Fla I (aa 1-15), Fla II (aa 11-25), Fla III (aa 32-45) and Fla IV (aa 88-102). Fla 30 is flagellin without an insert. ELISA titres are means of duplicate determinations. Only positive agglutination results are indicated, and are graded as weak $(+)$ or strong $(++)$ reactions.

\begin{tabular}{|lccccc|}
\hline Antibody & \multicolumn{5}{c|}{ ELISA titre (agglutination) } \\
\cline { 2 - 5 } & Fla 30 & Fla I & Fla II & Fla III & Fla IV \\
\hline mAbs & $<20$ & $<20$ & $2700(++)$ & $<20$ & $<20$ \\
mAb S-CFA/I 17:8 & $<20$ & $<20$ & $<20$ & $<20$ & $<20$ \\
mAb S-CFA/I 5:6 & & & & & \\
Antisera & $<20$ & $100(+)$ & $670(++)$ & $<20$ & $<20$ \\
Anti-peptide* & $<20$ & 60 & $730(++)$ & $490(++)$ & $760(++)$ \\
Anti-CFA/I subunit $\dagger$ & $<$ & & & \\
\end{tabular}

* Rabbit antiserum against peptide aa 1-25 of the protein sequence of the CFA/I fimbrial subunit.

† Mouse antiserum against CFA/I fimbrial subunits.

ELISA. When antisera against the synthetic CFA/I subunit peptide and CFA/I fimbrial subunits as well as the anti-CFA/I mAbs were tested for reactivity with purified hybrid flagellins, polystyrene microtitre plates (Dynatech) were coated with flagellin preparations in PBS $(0.145 \mathrm{M}$ sodium chloride, $0.15 \mathrm{M}$ sodium phosphate) $\left(1 \mu \mathrm{g} \mathrm{ml} \mathrm{m}^{-1}\right)$ and incubated at $37^{\circ} \mathrm{C}$ overnight. Conversely, when determining the reactivity of antisera against hybrid flagellins to CFA/I, plates were coated with CFA/I subunits $\left(0.5 \mu \mathrm{g} \mathrm{m}^{-1}\right)$. After blocking with $0.1 \%$ BSA in PBS at $37^{\circ} \mathrm{C}$ for $30 \mathrm{~min}$, antisera were serially diluted in PBS containing 0.1\% BSA and $0.05 \%$ Tween, added to the wells and incubated at room temperature for $60 \mathrm{~min}$. The presence of bound antibodies was then demonstrated by incubating the plates with horseradish-peroxidase-conjugated goat anti-mouse IgG (Jackson ImmunoResearch) and ophenylenediamine $/ \mathrm{H}_{2} \mathrm{O}_{2}$. Titres were determined as the reciprocals of dilutions giving an $A_{450}$ of 0.4 above background (Labsystems Multiscan PLUS) after $10 \mathrm{~min}$. All titrations were performed in duplicate.

Immunoelectron microscopy. Formvar-coated grids $(400$ mesh) were coated with suspensions of $S$. dublin expressing hybrid flagella for $2 \mathrm{~min}$. The coated grids were placed on a drop with $\mathrm{mAb}$ diluted in $1 \% \mathrm{BSA} / 0.05 \%$ Tween/PBS for $15 \mathrm{~min}$ and subsequently on drops with gold (10 $\mathrm{nm})$-labelled goat anti-mouse IgG (BioCell Research Laboratories) diluted $1: 30$ in $1 \%$ BSA $/ 0.05 \%$ Tween/PBS. After several washings with $1 \% \mathrm{BSA}$ in PBS and a final wash with distilled water, the samples were negatively stained with $1 \%(\mathrm{w} / \mathrm{v})$ ammonium molybdate (Sigma) and the grids were examined in an electron microscope (JEOL) at $80 \mathrm{kV}$.

Peptide synthesis. The synthesis of the peptide corresponding to the first $25 \mathrm{~N}$-terminal amino acids of the CFA/I subunit (VEKNITVTASVDPVIDLLQADGNAL) was performed with a Model 430 A Peptide Synthesizer (Applied Biosystems) as previously described (Rudin \& Svennerholm, 1996). After synthesis, the peptide was cleaved from the resin and the protecting groups were removed from the amino acids by acidic hydrolysis using anisole and ethanedithiol as scavengers. The peptide composition was confirmed by amino acid analysis, and purity was assessed by reverse-phase high- pressure liquid chromatography (Rudin \& Svennerholm, 1996).

Epitope analysis by Pepscan. A Multipin non-cleavable peptide kit and FMOC (9-fluorenylmethoxycarbonyl)-protected amino acids (Chiron Mimotopes) were used to synthesize sets of linear overlapping hexamer peptides corresponding to the N-terminal (aa 1-52), central (aa 85-114) and Cterminal (aa 121-147) parts of the CFA/I subunit protein by the Geysen pin method (Geysen et al., 1984). The peptides were synthesized on the tips of derivatized polyethylene pins in the configuration of 96-well microtitre plates and then activated with diisopropylcarbodiimide (Merck) and 1-hydroxybenzotriazole (Chiron Mimotopes), as described previously (Rudin \& Svennerholm, 1996). Geysen's capture ELISA (Geysen et al., 1984) was utilized with minor modifications. After an initial blocking step, the peptides on the pins were incubated with antisera against hybrid flagellins $(1 / 1000$ dilution) at room temperature for $2 \mathrm{~h}$. The pins were then washed and incubated with horseradish-peroxidase-conjugated goat anti-mouse IgG (1/2500 dilution) (Jackson ImmunoResearch) diluted in PBS $/ 1 \%$ sheep serum $/ 0.1 \%$ Tween 20 for $60 \mathrm{~min}$. Subsequently, the chromogenic substrate solution $\mathrm{H}_{2} \mathrm{O}_{2}$ /ABTS [diammonium 2,2'-azino-bis(3-ethylbenzthiazoline-6-sulphonate)] was added and the $A_{405}$ measured after $25 \mathrm{~min}$ on a Labsystem Multiscan Plus. The pins were reused after effective removal of the antibodies by sonication in disruption buffer ( $1 \%$ PBS, $1 \%$ SDS and $0 \cdot 1 \% 2-$ mercaptoethanol) at $65^{\circ} \mathrm{C}$ for $10 \mathrm{~min}$ and hot methanol treatment.

\section{RESULTS}

\section{Anti-CFA/I mAbs, anti-CFA/I peptide antibodies and polyclonal anti-CFA/l antibodies react with hybrid flagellins}

The mAbs S-CFA/I 17:8 and S-CFA/I 5:6, both obtained from mice immunized with dissociated CFA/I fimbrial subunits, were reacted with intact hybrid flagella expressed on the surface of $S$. dublin strain 

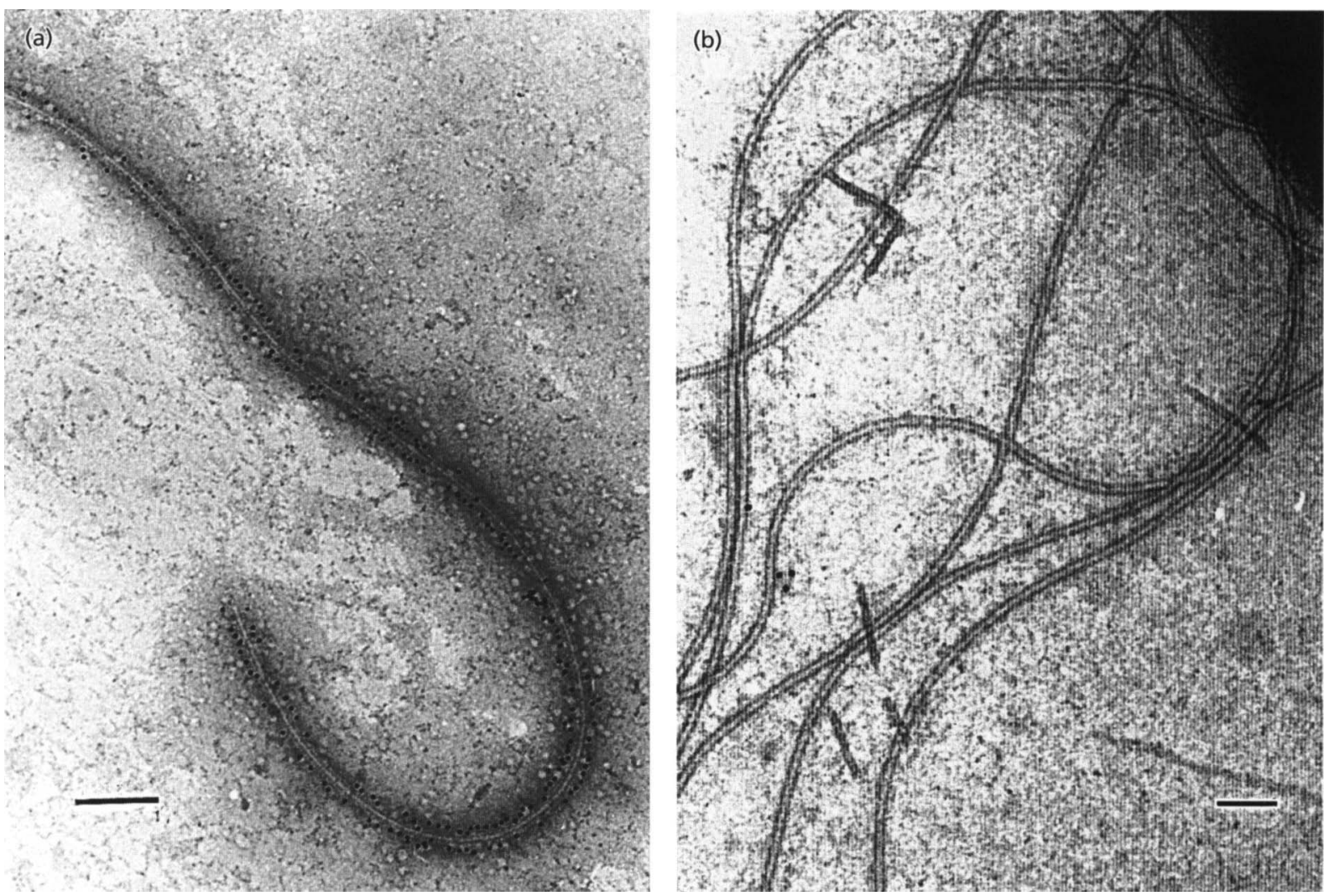

Fig. 1. Electron micrograph of immunogold labelling of Fla II flagellum bearing the CFAl-subunit-derived amino acid insert (aa 11-25) (a) and Fla 30 flagella without insert (b), expressed by recombinant $S$. dublin. Whole bacterial cells expressing flagella were labelled with mAb S-CFAll 17:8 at a final concentration of $72 \mu \mathrm{g} \mathrm{ml}^{-1}$ and negatively stained. Bars, $200 \mathrm{~nm}$.

Table 2. Inhibition of binding of CFAll-expressing bacteria to Caco-2 cells using antisera against $S$. dublin hybrid flagellins bearing inserted CFAl amino acid sequences

$\mathrm{mAb}$ S-CFA/I 17:8 was used at a final concentration of $14.4 \mu \mathrm{g}$ $\mathrm{ml}^{-1}$; all anti-flagellin sera were used in a final dilution of $1: 4$. Values are means from two separate experiments.

\begin{tabular}{|lc|}
\hline Antibody & $\begin{array}{c}\text { Caco-2 cells with adherent } \\
\text { CFA/I }\end{array}$ \\
\hline None & $22 \cdot 5 \pm 2 \cdot 5$ \\
mAb S-CFA/I 17:8 & $2 \cdot 7 \pm 0 \cdot 45$ \\
Anti-Fla 30 & $21 \cdot 1 \pm 3 \cdot 18$ \\
Anti-Fla I & $20 \cdot 5 \pm 0 \cdot 50$ \\
Anti-Fla II & $20 \cdot 6 \pm 3 \cdot 15$ \\
Anti-Fla III & $24 \cdot 0 \pm 1 \cdot 00$ \\
Anti-Fla IV & $23 \cdot 5 \pm 1 \cdot 67$ \\
\hline
\end{tabular}

SL5928 in agglutination tests or with purified hybrid flagellin in ELISA. Both of these mAbs had previously been shown to inhibit the CFA/I-mediated adhesion of ETEC bacteria to Caco-2 cells (Rudin et al., 1994). mAb
S-CFA/I 17:8 reacted specifically with hybrid Fla II flagella and Fla II flagellin (bearing CFA/I aa sequence 11-25) in agglutination tests and ELISA, respectively, whereas no reaction was detected with $\mathrm{mAb} \mathrm{S-CFA/I}$ 5:6 (Table 1). Rabbit antibodies raised against a synthetic linear peptide containing the first $25 \mathrm{~N}$ terminal amino acids of the CFA/I fimbrial subunit recognized only hybrid Fla I and Fla II flagella and flagellins in agglutination tests and in ELISA, respectively. Mouse polyclonal antibodies generated against dissociated CFA/I fimbrial subunits reacted with hybrid Fla II, Fla III and Fla IV flagellins and flagella in ELISA and in agglutination tests, respectively. However, these anti-CFA/I subunit antibodies did not react with Fla I flagella in agglutination tests and only weakly with hybrid Fla I flagellin in ELISA. The agglutination tests strongly indicated that the amino acid sequence inserts corresponding to regions of the CFA/I fimbrial subunit were surface-exposed on all recombinant Salmonella strains. Further evidence for surface exposure of the inserted CFA/I amino acid sequence in Fla II flagella was obtained from immunogold labelling experiments with $\mathrm{mAb}$ S-CFA/I 17:8. Very strong labelling was observed along the flagellar shafts of the $S$. dublin strain expressing hybrid Fla II flagella after reaction with $\mathrm{mAb}$ S-CFA/I 17:8, whilst no labelling was detected when the 

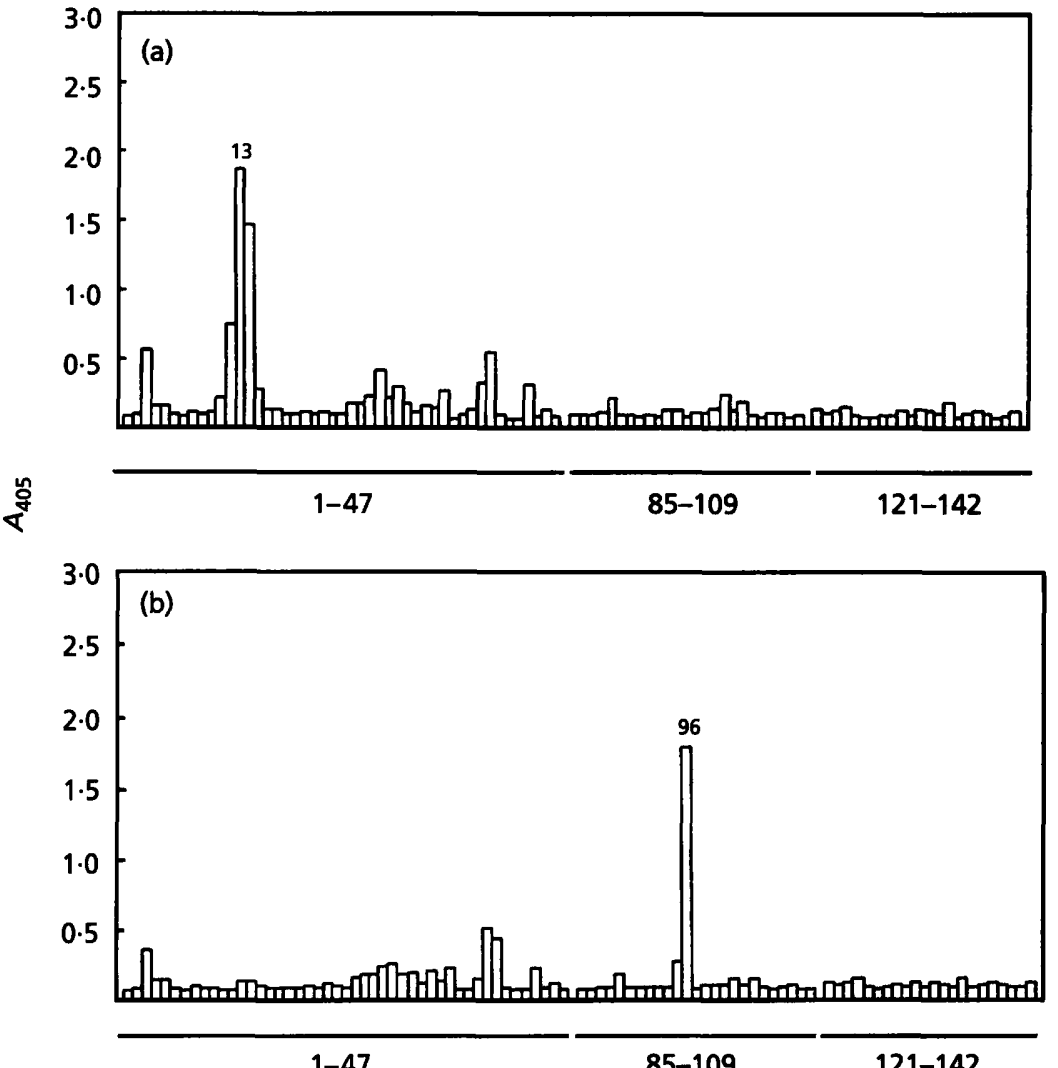

$85-109 \quad 121-142$
Fig. 2. Pepscan analysis of epitope reactivity of antisera against hybrid flagellins Fla II and Fla IV bearing CFAl subunit amino acid sequences. ELISA results (expressed as $A_{405}$ values) from testing anti-Fla II and anti-Fla IV mouse antisera against 94 hexamer peptides corresponding to the $\mathrm{N}$-terminal (aa 1-47), central (aa 85-109) and C-terminal (aa 121-142) parts of the CFAl fimbrial subunit sequence. The indicated peptide numbers refer to the first amino acid in the sequence of each hexapeptide on each pin. (a) Antiserum against hybrid flagellin Fla II expressing region II (aa 11-25) and (b) antiserum against hybrid flagellin Fla IV expressing region IV (aa 88-102), of the CFA/ fimbrial subunit sequence. Both antisera were diluted $1 / 1000$.
S. dublin strain expressing flagella without insert (Fla 30) was used (Fig. 1).

\section{Anti-hybrid flagellin antibodies do not inhibit binding of CFA/lexpressing bacteria to Caco-2 cells}

In a previous study we found that none of the antihybrid flagellin antisera could inhibit haemagglutination promoted by ETEC expressing CFA/I fimbriae (Luna et al., 1997). As a more physiological alternative to inhibition of haemagglutination we attempted to block the binding of CFA/I-expressing bacteria to Caco-2 enterocyte-like cells. No reduction in the numbers of Caco- 2 cells with adhering bacteria was observed in experiments carried out with antisera from mice immunized with the four different hybrid flagellins (Table 2). As a positive control, mAb S-CFA/I 17:8 inhibited the adherence of CFA/I-expressing bacteria to Caco-2 cells by approximately $90 \%$, confirming previously published results (Rudin et al., 1994).

\section{Pepscan analysis defines the CFA/l epitope specificity of antisera raised with hybrid Salmonella CFA/I flagellins}

To investigate whether the failure of the anti-Fla II antiserum to inhibit adhesion of CFA/I-expressing bacteria (Table 2) might be due to a different epitope specificity from mAb S-CFA/I 17:8, Pepscan analyses were performed to identify linear CFA/I epitopes recognized by the antibodies raised against the hybrid flagellins. In contrast to mAb S-CFA/I 17:8, which reacted specifically with the peptide sequence ${ }^{15}$ IDLLQ $^{19}$ (Rudin \& Svennerholm, 1996), the antibodies raised against purified hybrid flagellin Fla II bound strongly only to peptides 13 and 14 having the amino acid sequence ${ }^{14}$ VIDLL $^{18}$ in common (Fig. 2). Anti-Fla IV antiserum, which also possessed high antibody titres against CFA/I fimbrial subunits, was similarly submitted to Pepscan analysis. It reacted only with a short peptide sequence constituted by the hexapeptide ${ }^{96}$ FEAAAL ${ }^{101}$. Antisera against the other hybrid flagellin constructs, Fla I and Fla III, failed to react with specific linear peptides. Higher concentrations of anti-Fla I and anti-Fla III antisera were subsequently used, but the background increased dramatically and no specific reaction could be observed. Control non-immune serum showed a low background with no pre-existing specific antibodies to the peptides (data not shown).

\section{DISCUSSION}

Long-term protection against ETEC disease requires the induction of intestinal IgA against the various ETEC fimbriae to prevent colonization, which is the first event in ETEC pathogenesis (Holmgren \& Svennerholm, 1996). Although the majority of the CFA fimbrial epitopes are conformational, a few linear epitopes have been identified after immunization of monkeys with isolated CFA/I fimbrial subunits (Cassels et al., 1992). 
Antibodies against one linear epitope located in the $\mathrm{N}$ terminal part of the CFA/I subunit have been shown to interfere with the adherence of fimbriated bacteria to Caco-2 cells (Rudin et al., 1994). However, the development of peptide-based vaccines has been hampered by the low immunogenicity of synthetic peptides, particularly if administered on mucosae.

An alternative means of presenting linear epitopes to the mucosal immune system could be to use live recombinant Salmonella strains expressing hybrid flagellins (Newton et al., 1989). Such engineered strains have been shown to elicit humoral, mucosal and cellular immune responses after oral or parenteral immunization of animals (McEwen et al., 1992; Newton et al., 1989, 1991; Wu et al., 1989; Verma et al., 1995a, b). The successful application of this epitope delivery system to fimbrial antigens would require the cloning and expression of epitope(s) close to the receptor-binding site. In addition, the induced antibodies would need to display the appropriate specificities to bind and neutralize the fimbrial subunit in its polymeric form.

Previous reports suggested that only the terminal structural subunit of the CFA/I fimbriae exposes a receptor-binding domain (Bühler et al., 1991; Marron \& Smyth, 1995). This receptor-binding site probably includes the amino acids ${ }^{15}{ }^{1 D L L Q}{ }^{19}$ since the mAb SCFA/I 17:8, specific for this epitope, was very efficient in inhibiting adhesion of ETEC bacteria to Caco-2 cells and human enterocytes (Rudin \& Svennerholm, 1996; Rudin et al., 1996). Thus, the binding of $\mathrm{mAb}$ S-CFA/I 17:8 to hybrid flagellin Fla II, as shown both by agglutination tests and by immunogold labelling, indicated clearly that the expressed epitope had the right conformation for the mAb to bind strongly and was surface-exposed on the recombinant flagella. In addition, antibodies raised against the hybrid flagellin could recognize the CFA/I subunit in ELISA or immunoblots (Luna et al., 1997). Therefore, it was surprising that the anti-Fla II antibodies were not able to block binding of CFA/I-expressing bacteria to the Caco2 cells. However, this result was in line with previous experiments showing lack of inhibition of haemagglutination using these antisera (Luna et al., 1997).

Our findings using Pepscan analysis suggest that exposure of a sequence on the surface of the Salmonella flagellin does not ensure production of antibodies against all possible epitopes of that sequence. Thus, polyclonal antibodies against the Fla II insert (aa 11-25) reacted with only one linear epitope, composed of the sequence ${ }^{14}$ VIDLL ${ }^{18}$. The same epitope specificity was obtained in rabbits immunized with a synthetic peptide corresponding to the first $25 \mathrm{~N}$-terminal amino acids of the CFA/I fimbrial subunit and, similarly to our results, no significant inhibition of Caco-2 cell binding was found using this anti-peptide antiserum (Rudin \& Svennerholm, 1996). Therefore, the different epitope specificity of the anti-Fla II serum compared with that of $\mathrm{mAb}$ S-CFA/I 17:8 could be an explanation for the lack of inhibition of binding of CFA/I fimbriated bacteria to the Caco- 2 cells. Interestingly, the results obtained using two different ways (hybrid flagellin and synthetic peptide) of presenting the amino acid sequence in different animal species indicated that the sequence ${ }^{14}{ }^{\text {VIDLL }}{ }^{18}$ is the major linear epitope when the CFA/I $\mathrm{N}$-terminal peptide is presented to the immune system. With both immunization procedures, a minor change of the epitope specificity, in relation to the sequence recognized by the mAb S-CFA/I 17:8, seems to cause a significant alteration in the affinity of the antibodies to the native protein. Such different epitope specificities may also explain a previous report of antibodies raised against an epitope of hen egg-white lysozyme fused to $E$. coli flagellin, which failed to bind the same sequence in the native protein (Kuwajima et al., 1988).

Immunization of mice with the purified hybrid flagellin Fla IV (aa 88-102) also resulted in the generation of antibodies against a single linear epitope, the sequence ${ }^{96} \mathrm{FEAAAL}^{101}$. As far as we know, this is the first report of B-cell epitope specificity analysis of antibodies raised against sequences inserted in Salmonella flagellin and, in both of the antisera tested, the same restricted epitope specificity was obtained. We hypothesize that the conformation of the recombinant flagellins might favour the selection and presentation of unique sequences in the insert by antigen-presenting cells. Additional fine-specificity analysis of antisera raised against hybrid flagellins fused to other antigens may demonstrate if such strong preference for single linear epitopes extends to other flagellin constructs.

The analysis of the epitope specificity of serum antibodies of mice immunized with purified hybrid flagellin Fla II suggests that attempts to develop oral live Salmonella vaccines would probably not generate a mucosal immune response able to block adhesion of CFA/I-expressing bacteria to enterocytes. In contrast, previous attempts based on the expression of linear epitopes in the Salmonella flagellin system have succeeded in generating antibodies able to bind the $\mathbf{M}$ protein of Streptococcus pyogenes and the haemagglutinin of the influenza virus, leading to partial protection upon challenge (Newton et al., 1991; McEwen et al., 1992). As regards the CFA/I fimbrial subunit, a different conformation of the insert fused to the flagellin might be necessary for the generation of protective antibodies. The incorporation of amino acid residues bordering the heterologous insert in flagellin has been shown to affect the host immune response to the heterologous antigen (Verma et al., 1995a). A similar approach may also be applied to the CFA/I subunit sequence as a way to modify the conformation of the insert and, consequently, the specificity of the antibodies directed against the flagellin insert.

Although most of the previous studies using the Salmonella flagellin expression system have demonstrated the generation of serum antibodies against the heterologous insert, the epitope specificities of the antibodies have not been elucidated. Our results suggest that the fine specificity of linear epitopes recognized by anti- 
bodies raised against hybrid flagellin constructs may be important in terms of their interaction with the native protein.

\section{ACKNOWLEDGEMENTS}

The skilful assistance of Gudrun Wiklund in the purification of fimbriae and of Ella Olofsson in the production of mAbs is gratefully acknowledged, as well as the technical assistance of Marcelo M. Martins, Celso Pereira and Eduardo Camacho. We also thank Ann-Mari Svennerholm for support and valuable discussions, and Anna Helander for expert advice on the electron microscopy. This work was supported by the World Health Organization (WHO), the Swedish Agency for Research Cooperation in Developing Countries (SAREC), the Faculty of Medicine of Göteborg University, and by PADCT and FINEP. M.G.L. received a Fellowship from the Brazilian RHAE programme.

\section{REFERENCES}

Black, R. E. (1990). Epidemiology of travellers' diarrhea and relative importance of various pathogens. Rev Infect Dis 12, Suppl. 1, S73-S79.

Black, R. E. (1993). Epidemiology of diarrhoeal disease: implication for control by vaccines. Vaccine 11, 100-106.

Buhler, T., Hoschutzky, H. \& Jann, K. (1991). Analysis of colonization factor antigen $\mathrm{I}$, an adhesin of enterotoxigenic Escherichia coli O78:H11: fimbrial morphology and location of the receptor-binding site. Infect Immun 59, 3876-3882.

Cassels, F. J., Deal, C. D., Reid, R. H., Jarboe, D. L., Nauss, J. L., Carter, J. M. \& Boedeker, E. C. (1992). Analysis of Escherichia coli colonization factor antigen I linear B-cell epitopes, as determined by primate responses, following protein sequence determination. Infect Immun 60, 2174-2181.

Evans, D. G., Evans, D. J., Jr, Clegg, S. \& Pauley, J. A. (1979). Purification and characterization of the CFA/I antigen of enterotoxigenic Escherichia coli. Infect Immun 25, 738-748.

Gaastra, W. \& Svennerholm, A.-M. (1996). Colonization factors of human enterotoxigenic Escherichia coli (ETEC). Trends Microbiol 4, 444-452.

Geysen, H. M., Meloen, R. H. \& Barteling, S. J. (1984). Use of peptide synthesis to probe viral antigens for epitopes to a resolution of a single amino acid. Proc Natl Acad Sci USA 81, 3998-4002.

Gothefors, L., Åhrén, C., Stoll, B., Barua, D. K., Ørskov, F., Salek, M. A. \& Svennerholm, A. M. (1985). Presence of colonization factor antigens on fresh isolates of fecal Escherichia coli: a prospective study. J Infect Dis 152, 1128-1133.

Hoiseth, S. K. \& Stocker, B. A. D. (1981). Aromatic-dependent Salmonella typhimurium are non virulent and effective as live oral vaccines. Nature 291, 238-240.

Holmgren, J. \& Svennerhom, A.-M. (1996). Oral vaccines against cholera and enterotoxigenic Escherichia coli diarrhoea. In Mucosal Vaccines, pp. 241-253. Edited by H. Kyono, P. L. Ogra \& J. R. McGhee. New York: Academic Press.

Ibrahim, G. F., Fleet, G. H., Lyons, M. J. \& Walker, R. A. (1985). Method for the isolation of highly purified Salmonella flagellins. J Clin Microbiol 22, 1040-1044.

Kuwajima, G., Asaka, J.-I., Fujiwara, T., Fujiwara, K., Nakano, K. \& Kondoh, E. (1988). Presentation of an antigenic determinant from hen egg-white lysozyme on the flagellar filament of Escherichia coli. Biotechnology 6, 1080-1086.

Lopez-Vidal, Y., Klemm, P. \& Svennerholm, A.-M. (1988). Monoclonal antibodies against different epitopes on colonization factor antigen I of enterotoxin-producing Escherichia coli. J Clin Microbiol 26, 1967-1972.

Luna, M. G., Martins, M. M., Newton, S. M. C., Costa, S. O. P., Almeida, D. F. \& Ferreira, L. C. S. (1997). Cloning and expression of colonization factor antigen I (CFA/I) epitopes of enterotoxigenic Escherichia coli (ETEC) in Salmonella flagellin. Res Microbiol 148, 217-228.

McConnell, M. M., Chart, H. \& Rowe, B. (1989). Antigenic homology within human enterotoxigenic Escherichia coli fimbrial colonization factor antigens: CFA/I, coli-surface-associated antigens CS1, CS2, CS4 and CS17. FEMS Microbiol Lett 61, 105-108.

McEwen, J., Levi, R., Horwitz, R. J. \& Arnon, R. (1992). Synthetic recombinant vaccine expressing influenza haemagglutinin epitope in Salmonella flagellin leads to partial protection in mice. Vaccine 10, 405-411.

Marron, M. B. \& Smyth, C. J. (1995). Molecular analysis of the cso operon of enterotoxigenic Escherichia coli reveals that CsoA is the adhesin of CS1 fimbriae and that the accessory genes are interchangeable with those of the cfa operon. Microbiology 141, 2849-2859.

Newton, S. M. C., Jacob, C. O. \& Stocker, B. A. D. (1989). Immune response to cholera toxin epitope inserted in Salmonella flagellin. Science 244, 70-72.

Newton, S. M. C., Kotb, M., Poirier, T. P., Stocker, B. A. D. \& Beachey, E. H. (1991). Expression and immunogenicity of a streptococcal M protein epitope inserted in Salmonella flagellin. Infect Immun 59, 2158-2165.

Rudin, A. \& Svennerholm, A.-M. (1996). Identification of a crossreactive continuous B-cell epitope in enterotoxigenic Escherichia coli colonization factor antigen I. Infect Immun 64, 4508-4513.

Rudin, A., McConnell, M. M. \& Svennerholm, A.-M. (1994). Monoclonal antibodies against enterotoxigenic Escherichia coli colonization factor antigen (CFA/I) that cross-react immunologically with heterologous CFAs. Infect Immun 62, 4339-4346.

Rudin, A., Olbe, L. \& Svennerholm, A.-M. (1996). Monoclonal antibodies against fimbrial subunits of colonization factor antigen I (CFA/I) inhibit binding to human enterocytes and protect against enterotoxigenic Escherichia coli expressing heterologous colonization factors. Microb Pathog 20, 35-45.

Svennerholm, A.-M., Holmgren, J. \& Sack, D. A. (1989). Development of oral vaccines against enterotoxigenic Escherichia coli. Vaccine 7, 196-198.

Verma, N. K., Ziegler, H. K., Wilson, M., Khan, M., Safley, S., Stocker, B. A. D. \& Schoolnik, G. K. (1995a). Delivery of class I and class II MHC-restricted T-cell epitopes of listeriolysin of Listeria monocytogenes by attenuated Salmonella. Vaccine 13, 142-150.

Verma, N. K., Ziegler, H. K., Stocker, B. A. D. \& Schoolnik, G. K. (1995b). Induction of a cellular immune response to a defined Tcell epitope as an insert in the flagellin of a live vaccine strain of Salmonella. Vaccine 13, 235-244.

Wu, J. Y., Newton, S. M. C., Judd, A., Stocker, B. A. D. \& Robinson, W. S. (1989). Expression of immunogenic epitopes of hepatitis B surface antigen with hybrid flagellin proteins by a vaccine strain of Salmonella. Proc Natl Acad Sci USA 26, 4726-4730.

Received 11 February 1997; revised 10 June 1997; accepted 20 June 1997. 